\title{
Significance of QRS duration in non-ST elevation myocardial infarction.
}

\author{
Chinualumogu Nwakile \\ Einstein Medical Center \\ Bhaskar Purushottam \\ Mount Sinai Health Systems \\ Vikas Bhalla \\ Einstein Medical Center \\ Daniel Ukpong \\ Einstein Medical Center
}

Mahek Shah

Einstein Medical Center

Follow this and additional works at: https://jdc.jefferson.edu/cardiologyfp

Part of the Cardiology Commons

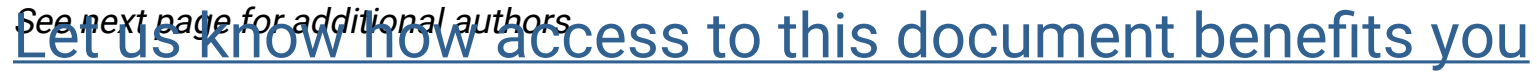

\section{Recommended Citation}

Nwakile, Chinualumogu; Purushottam, Bhaskar; Bhalla, Vikas; Ukpong, Daniel; Shah, Mahek; Yun, Jeong; Morris, D Lynn; and Figueredo, M.D., Vincent M., "Significance of QRS duration in non-ST elevation myocardial infarction." (2015). Division of Cardiology Faculty Papers. Paper 53. https://jdc.jefferson.edu/cardiologyfp/53

This Article is brought to you for free and open access by the Jefferson Digital Commons. The Jefferson Digital Commons is a service of Thomas Jefferson University's Center for Teaching and Learning (CTL). The Commons is a showcase for Jefferson books and journals, peer-reviewed scholarly publications, unique historical collections from the University archives, and teaching tools. The Jefferson Digital Commons allows researchers and interested readers anywhere in the world to learn about and keep up to date with Jefferson scholarship. This article has been accepted for inclusion in Division of Cardiology Faculty Papers by an authorized administrator of the Jefferson Digital Commons. For more information, please contact: JeffersonDigitalCommons@jefferson.edu. 


\section{Authors}

Chinualumogu Nwakile; Bhaskar Purushottam; Vikas Bhalla; Daniel Ukpong; Mahek Shah; Jeong Yun; D Lynn Morris; and Vincent M. Figueredo, M.D. 


\section{Significance of QRS Duration in Non-ST Elevation Myocardial Infarction}

Chinualumogu Nwakile $\mathrm{MD}^{1}$, Bhaskar Purushottam $\mathrm{MD}^{4}$, Vikas Bhalla MD, MSc${ }^{1}$, Daniel

Ukpong $\mathrm{MD}^{1}$, Mahek Shah $\mathrm{MD}^{1}$, Jeong Yun MD, $\mathrm{MPH}^{3}$, D. Lynn Morris $\mathrm{MD}^{1,2}$, Vincent M Figueredo $\mathrm{MD}^{1,2}$.

${ }^{1}$ Einstein Institute for Heart and Vascular Health, Einstein Medical Center, Philadelphia, PA.

${ }^{2}$ Sidney Kimmel College of Medicine at Thomas Jefferson University, Philadelphia, PA. ${ }^{3}$

Brigham and Women's Hospital, Boston, MA. ${ }^{4}$ Mount Sinai Heart, Mount Sinai Health Systems, New York, NY.

Key words: ventricular fibrillation, ventricular tachycardia, thirty day mortality, one year mortality, acute coronary syndrome

Running title: Significance of QRS Duration in Non-ST Elevation Myocardial Infarction

Disclosures: No conflicts of interest

Corresponding author:

Vincent M Figueredo, MD

Einstein Heart and Vascular Center

5501 Old York Road, Levy 3232

Philadelphia, PA 19141

Phone: 215-456-8991

Fax: 215-456-3533

Email: figueredov@einstein.edu 
Several studies have examined the significance of prolonged QRS duration, in the absence of bundle branch block (BBB), for predicting mortality in patients post ST elevation myocardial infarction (STEMI). ${ }^{1,2}$ Few have studied this relationship in the non ST elevation myocardial infarction (NSTEMI) population, especially in the post thrombolytic era. The primary endpoints of this study were to determine whether prolonged admission QRS in the absence of BBB predicts 30 day and one year mortality in NSTEMI patients. A secondary endpoint was to determine the relationship between prolonged QRS and occurrence of in-patient ventricular tachyarrhythmias after NSTEMI.

One thousand nine hundred and sixty patients admitted to Einstein Medical Center, Philadelphia from August 1, 2006 to August 31, 2011 with a diagnosis of NSTEMI were screened. The study protocol was approved by the Einstein Institutional Review Board. The author(s) of this manuscript have certified that they comply with the principles of ethical publishing in the International Journal of Cardiology ${ }^{3}$.

NSTEMI was diagnosed on the basis of cardiac symptoms and electrocardiographic changes consisting of ST depression in two contiguous leads and positive troponins in accordance with existing guidelines ${ }^{4}$. Patients with known prior QRS $\geq 110 \mathrm{~ms}$, BBB, paced rhythm or incomplete data sets were excluded. Admission EKGs, as well as telemetry data, were reviewed to determine QRS duration and development of inpatient ventricular arrhythmias (ventricular tachycardia (VT) and ventricular fibrillation (VF)) during the index hospital stay. QRS durations from fifty random EKGs were measured by both manual and electronic means and then compared to ascertain accuracy and reliability of the electronic method of collection which was eventually used for EKG measurements $\left(\mathrm{R}^{2}=0.96, \mathrm{P}<0.0001\right)$. Data on patient demographics, clinical characteristics, baseline hemodynamic parameters, ejection fraction (obtained from transthoracic 
echocardiogram reports) and type of intervention performed (percutaneous coronary intervention (PCI) or coronary artery bypass graft (CABG)) were collected. Mortality at 30 days and one year were determined from hospital records and the publicly accessed social security death index website.

Baseline characteristics of patients with a prolonged $Q R S \geq 110$ ms versus those with a QRS $<100 \mathrm{~ms}$ were compared using independent-sample $t$ tests for continuous variables and chisquare for discrete variables. Multivariate Cox proportional hazards regression models were used to evaluate independent predictors of mortality. Kaplan-Meier method was used for generating survival curves and compared using the log-rank test. Effect of each variable was expressed as an odds ratio $(\mathrm{OR})$ and confidence interval $(\mathrm{CI})$. A p value $<0.05$ was considered statistically significant. Statistical analyses were performed using SPSS, version 22.

The final cohort consisted of 1539 patients with mean age of 66+14year, 51\% were female and the average QRS for the entire cohort was $90.5 \pm 13.5 \mathrm{~ms}$. Demographics, clinical and hemodynamic characteristics are listed in Table 1 . A cut off of QRS $\geq 110 \mathrm{~ms}$ was used as it yielded the best specificity, negative predictive value and accuracy for predicting mortality (91\%, 91\% and 84\%, respectively). On multivariate analysis, patients with QRS $\geq 110 \mathrm{~ms}$ had increased 30-day mortality $(\mathrm{HR}=1.9,95 \% \mathrm{CI} 1.10-3.23 ; \mathrm{p}=0.02)$ (Table 1$)$ and one-year mortality $(\mathrm{HR}=1.44,95 \% \mathrm{CI} 1.002-2.059 ; \mathrm{p}=0.05)$ (Table 1$)$, even after adjusting for known coronary artery disease risk factor variables, chronic kidney disease and revascularization. Chronic kidney disease was predictive of one year mortality, but not for 30 day mortality (Table 1). KaplanMeier curves stratified by QRS $\geq 110 \mathrm{~ms}$ versus QRS $<110 \mathrm{~ms}$ showed an increase in both 30 day and one-year mortality in patients with prolonged QRS (Figure 1).

During hospitalization of NSTEMI patients with QRS $\geq 110 \mathrm{~ms}, 21.8 \%$ experienced VT and 3.2\% 
had VF compared to $10.3 \%$ and $0.9 \%$ of patients with QRS $<110 \mathrm{~ms}$. The odds of having inpatient ventricular tachycardia and ventricular fibrillation was $2.4(\mathrm{OR}=2.4,95 \% \mathrm{CI} 1.5-3.8)$ and 3.6(OR=3.6, 95\%CI 1.2-11.2) times higher in patients with $\mathrm{QRS} \geq 110 \mathrm{~ms}$ compared to patients with QRS $<110 \mathrm{~ms}$.

Studies have shown that prolonged QRS duration due to the presence of bundle branch block increased short term mortality in patients presenting with ST elevation myocardial infarction $(\mathrm{STEMI})^{5,6}$. Even in the absence of bundle branch block, prolonged QRS has been shown to predict increased mortality in STEMI patients ${ }^{2,7}$. Several hypotheses have been put forward to explain this finding. Some postulated that QRS prolongation might be due to scar tissue formation affecting the conduction system, which could predispose to reentry and ultimately ventricular arrhythmias ${ }^{8,9}$. Others hypothesized that QRS prolongation post STEMI may be due to late potentials which are large enough to affect the surface EKG and they point to extensive infarcts and involvement of the interventricular system and hence, increased mortality ${ }^{7}$. Few studies have examined this relationship in NSTEMI patients.

Our study demonstrates that a QRS $\geq 110 \mathrm{~ms}$ in patients presenting with NSTEMI is associated with increased short and long term mortality in the absence of bundle branch block. We believe that the initial QRS duration measured upon presentation with NSTEMI can help with stratification of this patient population as we demonstrated that patients with NSTEMI and QRS $\geq 110 \mathrm{~ms}$ have a $90 \%$ increased risk of dying within 30 days. Given that only 14 patients need to be aggressively treated to save one life at 30 days post NSTEMI, it is not unreasonable to use the QRS duration as a tool to stratify at risk patients into a group that might benefit from more aggressive care. For example these patients could be discharged with a wearable cardioverter defibrillator to help terminate ventricular arrhythmias and therefore prevent sudden 
cardiac death versus having them routinely followed up ${ }^{10}$.

Study limitations included knowing the specificcause of death after patients left the hospital, such that 30 day mortality was all cause mortality, which is less reliable in demonstrating a direct cause and effect relationship. Finally, our subject population was predominantly black which might limit generalizing our results to other populations.

In conclusion, $\mathrm{QRS}$ duration $\geq 110 \mathrm{~ms}$, in the absence of a $\mathrm{BBB}$, is an independent predictor of 30-day and one-year mortality after NSTEMI. A QRS duration $\geq 110 \mathrm{~ms}$ after NSTEMI is also associated with increased occurrence of in-patient ventricular arrhythmias. 


\section{BIBLIOGRAPHY}

1. Kalahasti V, Nambi V, Martin DO, Lam CT, Yamada D, Wilkoff BL, Niebauer MJ, Jaeger FJ, Tchou PJ, Chung MK. QRS duration and prediction of mortality in patients undergoing risk stratification for ventricular arrhythmias. Am J Cardiol 2003 Oct; 92(7):798-803

2. Nwakile C.C, Purushottam B, Yun J, et al QRS Duration Predicts Inpatient Ventricular Arrhythmias and 30 Day Mortality Following ST Elevation Myocardial Infarction. Int J of Cardiol, Heart and vessels 2014 Volume 5: Pages 42-44

3. Coats AJS and Shewan LG. Statement on Authorship and Publishing Ethics in the International Journal of Cardiology. Int J Cardiol 2011; 153: 239-40

4. O'Gara P.T et al 2013 ACCF/AHA Guideline for the Management of ST-Elevation Myocardial Infarction: A Report of the American College of Cardiology Foundation/American Heart Association Task Force on Practice Guidelines. Circ December 2012

5. Sgarbossa E.B, Pinski S.L, Topol E.J, et al. Acute myocardial infarction and complete bundle branch block at hospital admission: clinical characteristics and outcome in the thrombolytic era. GUSTO-I Investigators. Global Utilization of Streptokinase and t-PA [tissue-type plasminogen activator] for Occluded Coronary Arteries. J Am Coll Cardiol 1998;31(1):105-10

6. Bauer, A., Watanabe, M.A., Barthel, P. et al, QRS duration and late mortality in unselected post-infarction patients of the revascularization area. Eur Heart J. 2006;27:427-433

7. Hathaway WR, Peterson DE, Wagner GS, Granger CB, Zabel KM, Pieper KS, Clark KA, Woodlief LH, Califf RM. Prognostic significance of the Initial Electrocardiogram in patients with acute myocardial Infarction. JAMA 1998; 279:387-391 
8. Tjandrawidjaja MC, Fu Y, Westerhout CM, Wagner GS, Granger CB, Armstrong PW; APEX-AMI Investigators. Usefulness of QRS score as a strong prognostic marker in patients discharged after undergoing primary PCI for STEMI. Am J Cardiol 2010 Sep 1;106(5):630-4

9. Zipes DP. Cardiac electrophysiology: promises and contributions. J Am Coll Cardiol 1989: $13: 1329-1352$

10. Zishiri E.T, Williams S, Cronin E.M, et al. Early Risk of Mortality after Coronary Artery Revascularization in Patients with Left Ventricular Dysfunction and Potential Role of the Wearable Cardioverter Defibrillator. Circ Arrhythm Electrophysiol 2010;33:353-367 


\section{Table Legends}

Table 1: Multivariate Analysis for QRS $\geq 110 \mathrm{~ms}$ and:

(a) 30 day all-cause mortality

(b) One year all-cause mortality

\section{Figure Legends}

Figure 1: Kaplan-Meier Survival Estimates (30 Day Mortality and One Year Mortality) 
Table 1

Multivariate predictors for $Q R S \geq 110 \mathrm{~ms}$ and 30 day or 1 year all-cause mortality

\begin{tabular}{|l|l|l|}
\hline 30 DAY MORTALITY & HR (95\% CI) & P value \\
\hline QRS duration on admission & $1.88(1.10-3.23)$ & 0.02 \\
\hline Age & $1.04(1.02-1.06)$ & 0.01 \\
\hline Revascularization & $0.24(0.13-0.45)$ & 0.00 \\
\hline Ejection Fraction & $0.27(0.76-0.95)$ & 0.04 \\
\hline $\mathbf{1}$ YEAR MORTALITY & HR (95\% CI) & P value \\
\hline QRS on admission & $1.44(1.002-2.059)$ & 0.05 \\
\hline Age & $1.05(1.04-1.06)$ & 0.00 \\
\hline Chronic Kidney Disease & $1.60(1.25-2.06)$ & 0.00 \\
\hline Ejection Fraction & $0.30(0.14-0.63)$ & 0.00 \\
\hline Revascularization & $0.38(0.28-0.51)$ & 0.00 \\
\hline
\end{tabular}

Figure 1 
Kaplan-Meier Survival Estimates (30 Day Mortality and One Year Mortality)

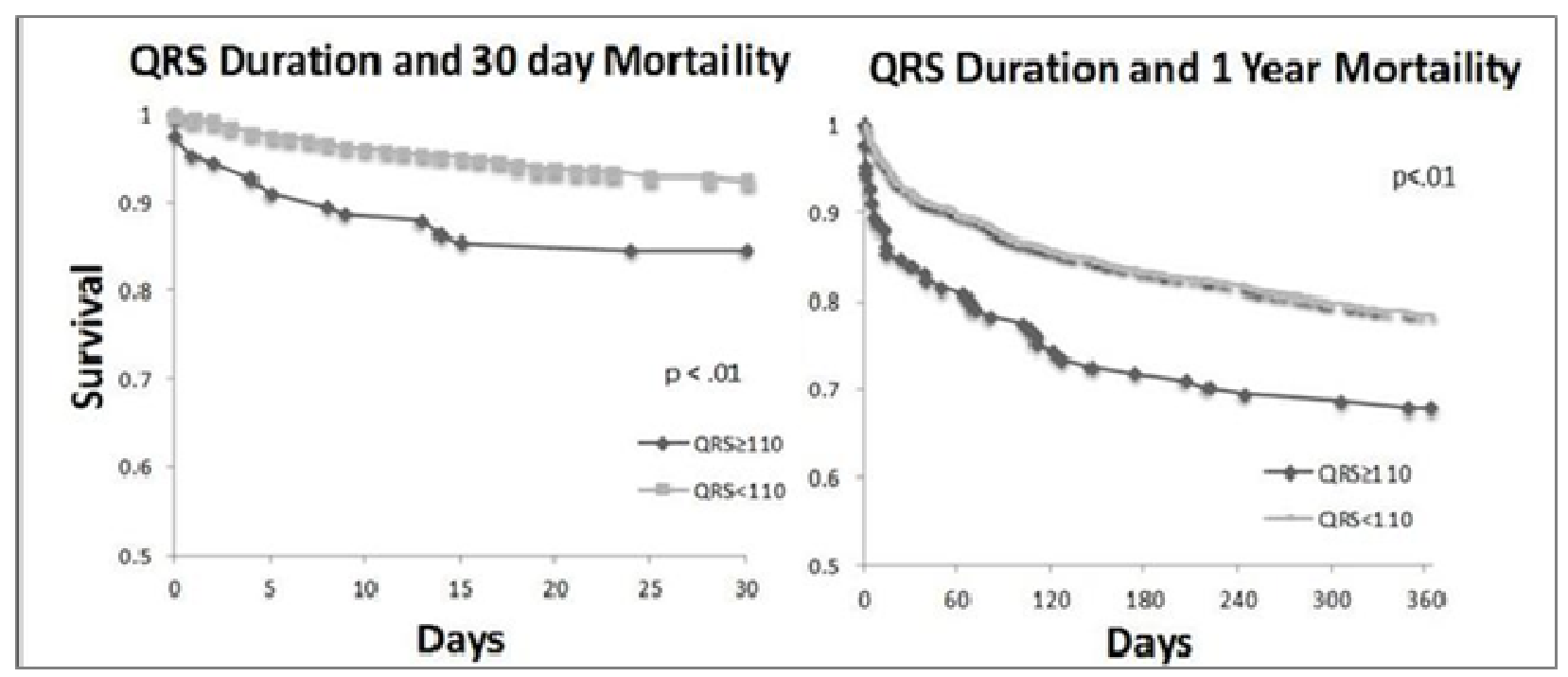

